\section{Opinion}

\section{"Corresponding author}

Quek Kia Fatt, PhD

Associate Professor Jeffrey Cheah School of Medicine and Health Sciences Monash University Malaysia

Jalan Lagoon Selatan

47500 Bandar Sunway

Selangor Darul Ehsan

Malaysia

Tel. +603-55146313

Fax: $+603-55146323$

E-mail: Quek.Kia.Fatt@monash.edu

Volume 1 : Issue 2

Article Ref. \#: 1000PHOJ1107

\section{Article History}

Received: March $15^{\text {th }}, 2016$

Accepted: April $6^{\text {th }}, 2016$

Published: April $7^{\text {th }}, 2016$

\section{Citation}

Quek KF. Non-communicable diseases - a major problem worldwide. Public Health Open J. 2016; 1(2): 3235. doi: 10.17140/PHOJ-1-107

\section{Copyright}

(C)2016 Quek KF. This is an open access article distributed under the Creative Commons Attribution 4.0 International License (CC BY 4.0), which permits unrestricted use, distribution, and reproduction in any medium, provided the original work is properly cited.

\title{
Non-Communicable Diseases: A Major Problem Worldwide
}

\section{Quek Kia Fatt, PhD*}

Jeffrey Cheah School of Medicine and Health Sciences, Monash University Malaysia, Jalan Lagoon Selatan, 47500 Bandar Sunway, Selangor Darul Ehsan, Malaysia

Non-Communicable Diseases (NCDs) are a worldwide major problem. NCDs are accounted for over 36 million deaths each year and highly prevalent in low- and middle-income countries. ${ }^{1}$ It is estimated that 16 million people die prematurely before reaching the age of $70 .^{2}$ It is also the leading cause of hospital admission and premature deaths. NCD comprises diabetes, asthma, hypertension, heart attacks, cancer, obesity, depression etc. Some of the major NCDs such as diabetes, hypertension, dyslipidemia are attributed to unhealthy lifestyle behaviours. Four prominent risk factors namely smoking, physical inactivity, alcohol and unhealthy diet have been found to be associated with NCD deaths. Tables 1 and 2 show worldwide mortality in 2012 based on the 4 main non-communicable diseases and total, premature NCD and preventable risk factors relating to deaths respectively.

\begin{tabular}{|c|c|}
\hline Non-Communicable Diseases & Mortality \\
\hline Cardiovascular Diseases & 17.5 million \\
\hline Cancer & 8.20 million \\
\hline Respiratory Diseases & 4 million \\
\hline Diabetes & 1.5 million \\
\hline
\end{tabular}

\begin{tabular}{|c|c|}
\hline Mortality and risk factors & Data based on year $\mathbf{2 0 1 2}$ \\
\hline Overall NCD mortality & 38 million deaths (out of 56 million deaths globally) \\
\hline Premature NCD mortality & $48 \%$ of NCD deaths before age 70 (in low- and middle-income countries) \\
\hline Preventable risk factors & $80 \%$ of premature heart disease, stroke and diabetes can be prevented \\
\hline
\end{tabular}

Table 2: Total, premature NCD and preventable risk factors relating to deaths worldwide. ${ }^{4}$

\section{REASONS NON-COMMUNICABLE DISEASES ON THE RISE}

Numerous efforts have been taken to tackle NCDs. For example in diabetes, health awareness campaigns with regards to diet, physical activity, education and health policies have been implemented. Although some awareness have been created, it is hardly successful. The awareness through education is important in preventing NCDs. According to a study done by Snyder on the effectiveness of health communication campaigns, it was noted that if the awareness were to focus on the objective which is to reduce the prevalence or incidence of the disease, it may not necessarily lead to behavioural changes and would be better to focus on the aims of behavioural changes. ${ }^{5}$

It has been shown in many studies that NCDs such as diabetes and risk factors are inversely associated with education ${ }^{6}$ and low education is not a hindrance to behavioural lifestyle changes. ${ }^{7}$ The knowledge of the progression and symptomatology of the disease as well as the awareness and management of the disease and the risk factors such as diabetes and hypertension that could be prevented by lifestyle changes are still lacking among the general population. This was noted in a diabetes prevention program in Finland (FIN-D2D) where awareness of diabetes and its risk factors were raised and which resulted in lifestyle changes as well as health behaviour and early facilitation of diagnosis and management of type II diabetes. ${ }^{8}$ However, the 
findings were limited to self-reported questionnaires and misclassification which cannot be ruled out.

However, on the other extreme spectrum, especially in the urban population where the general knowledge of the disease is far better than the rural population, the disease is on the rise. Some urban people are less critical in their behaviour and attitude and pay less attention. Some studies have been done to focus on the knowledge, attitude and practices in some populations. For example, a study of hypertension in Gandhinagar, Gujarat has shown subjects having good knowledge of the disorder but are poor in their attitude and practice..$^{9,10}$

Similarly a study in Nepal on cardiovascular health, among those with satisfactory knowledge, only a small percentage had highly satisfactory attitude and satisfactory/highly satisfactory practices. ${ }^{11}$ This is one of the issues why NCD is difficult to tackle. When these people are eventually diagnosed with $\mathrm{NCD}(\mathrm{s})$, they are aware of the contributing factors to these diseases but it may be too late as the disease may have developed for quite some time before diagnosis.

The availability of many fast food outlets, food stalls selling unhealthy food and drinks are also contributing to the risk of NCDs. Since these fast food outlets are easily accessible to the parents and their children, it is not surprising to see the rapid rise of NCDs. There are many different types of food sold on the streets which contain high carbs and fats as well as carbonated and sweetened drinks which are widely sold by traders and consumed by consumers. The availability of food after midnight in some countries and 24 hour fast food outlets have given more opportunities for people to access more food. Also there are many meetings held in the government and private offices where food and drinks are frequently provided.

The preparation and amount of food at home is one of the contributing factors to obesity and NCDs. The person who prepares the food has no knowledge of what type of healthy food to prepare. Most of the time, the amount of food prepared in a family is usually in excess. The excess is usually either refrigerated or consumed later rather than discarded.

People also tend to spend more time in the office and in front of their computers. Most of the work nowdays involves paper work, report writing, emailing etc. and these make them less active and it is not good for health. These are few reasons why people get obese these days. A systematic review and metaanalysis study by Kivimaki et al showed that people who spend long working hours have higher risk of getting coronary heart disease and stroke. ${ }^{12}$

People tend to focus more on their work/job and pay less attention to exercise or physical activity. The priority placed on routine work is one of the reasons why people tend to take exercise less seriously. The lack of proper place or lack of facilities for physical activity is also one of the reasons why people find it hard to do physical activity. Apart from this, there are issues of lack of time due to family commitments which they need to address.

Smoking and consumption of alcohol are well-known contributors to NCDs. ${ }^{13}$ Ignorance on the risk of smoking and alcohol consumption are high as the effects can be observed over the years of exposure. The labelling of the cigarette package with pictures showing the consequences of smoking has not been successful as people still continue to smoke. There is also a new alternative trend of smoking called e-cigarettes (vaping) which is equally or more detrimental to health compared to conservative tobacco smoking. Schweitzer et al has shown that nicotine and nicotine-free e-cigarette solutions have damaging effects on the lungs. ${ }^{14}$ Despite knowing the consequences, people still ignore the warning and continue to vape.

In terms of prevention of NCDs, according to a worldwide study, physical inactivity can contribute to $6-10 \%$ of NCDs such as type II diabetes, coronary heart disease, breast and colon cancers. ${ }^{15}$ Improving on physical activity can help to reduce the NCDs as well as increase life expectancy. No one can argue that physical activity is indeed important in order to prevent NCDs as highlighted in this study as well as in others. To achieve this, the individual need to take his/her own initiative to ensure that the physical activity is taken seriously. Healthcare professionals can only advice but in the end, it is the general public that need to take the initiative. The government/municipal councils should build more parks in the residential areas so that the public can engage in physical activity regardless of urban or rural areas.

With regards to smoking, the government has two choices; ban or increase cigarettes prices in order to reduce smoking among the general public. However, banning tobacco is not possible as it has been a source of income for many countries through implementation of taxes. Due to the availability and affordability of e-cigarettes, more people are switching to vaping. The government should ban e-cigarettes as it could cause more harm than the conventional smoking.

More effort is needed for the government to control the sales of carbonated drinks in the market. Although this is hard to implement, the least the government could do is to instruct the relevant companies to reduce the sugar level in the cans before selling them to the consumers. The government should also stop giving licences to new fast food chains to be set up. Currently, there are many available fast food outlets which provide unhealthy food.

More awareness on NCDs should be made available either in the media or via campaigns. The campaigns should be continously highlighted as usually done in cinemas, television, social media etc. and not for a short period of time. The government and Ministry of Health should from time to time organize and carry out awareness campaigns at the community level and hospital/clinics to create awareness so that the public knows that 
the government is very concerned about their health.

Each clinic or hospital should have a wellness or NCD clinic with one dedicated nurse attached to it. Most of the time, doctors do not have much time to spend on providing detailed information and to educate the patients on lifestyles as well as for the patients to seek further advice or ask more questions. In order to treat a patient successfully, there is a need to know the patient's medical history, social history and the difficulties the patient is facing. By setting up a dedicated clinic for this purpose, the patients will be able to spend more time with health care professionals to ask more questions and to seek advice as well as for monitoring purposes.

The school education system should also place the importance of implementing subjects related to nutrition and health. The curriculum needs to be updated from time to time to cater for the country's needs. It is vital that school children are taught early so that they are aware of it. Most of the time, children are influenced by their parents. If the parents have no proper awareness, the children may follow their parents footsteps.

\section{CONCLUSION}

Preventing NCDs is not an easy task. A lot of effort need to be taken to address the issue. The government and the public need to seriously pay more attention and take necessary action so that NCDs can be reduced. The role of government is important and it requires good leadership as well as policy development and implementation.

Apart from that, there is a need to incorporate all strategies in order to prevent NCDs. For example, there are some successful community intervention programs for diabetes such as Kerala Diabetes Intervention Studies, ${ }^{16,17}$ Da Qing Diabetes Prevention Study, ${ }^{18}$ Finnish Diabetes Prevention Study (DPS $)^{19}$ which incorporated various strategies such as peer support, lifestyle changes/modification (diet, physical activity), education sessions, health education booklet etc.

Most of the premature deaths are due to NCDs that are preventable. If the public is still apathetic to their actions, the NCDs will increase and the government will have to spend more money on the treatment, resources and the country suffers from the loss of productivity. Before it is too late, appropriate actions are required and all the contributing factors to NCDs need to be addressed. It is vital for the community/public to take charge of their own health and not place the responsibility solely on the care of healthcare providers. The public also need to be aware that NCDs kill and action needs to be taken before they develop the condition(s).

The nine global targets for prevention and control of NCDs set by WHO: reducing alcohol consumption, increasing physical activity, reducing salt/sodium intake, reducing the use of tobacco, containing hypertension, slowing down the rise of diabetes and obesity, improving the treatment coverage for prevention of heart attacks and strokes, access to basic technologies and essential medicines, as well as reducing $25 \%$ of premature deaths of the four major NCDs by $2025^{2}$, are realistic and achievable.

\section{FUTURE DIRECTION}

To reduce the burden of NCDs, the government needs to play an active role not only to implement policies but also to ensure that the strategies are fully implemented and monitored. At the lower level, there is a need to ensure that the intervention program is tailor made accordingly to individual needs. Each health clinic/health centre should have a wellness centre dedicated to NCDs to provide counseling and also to monitor progress. The needs of each individual are different from one another. As such there is a need to customize the intervention package according to individual needs.

Further to the management of existing population with NCDs, the government, particularly the Ministry of Health should focus on the prevention of NCDs by targetting the high risk groups. Apart from that, Ministry of Health and Nutrition Society should endorse a recommended standardized nutritional menu with proper nutritional standards to enable the public to use it as a dietary guide.

Awareness, attitude and practice are the most important contributing factors for NCDs. The strategies need to focus on those who are unaware of the NCDs and on those who are aware but with poor attitude and practice and should focus on individual or group needs rather than focus on the general group.

\section{REFERENCES}

1. World Health Organization. Global Status Report on Non-Communicable Diseases 2010. Geneva, Switzerland. Web site. http://www.who.int/nmh/publications/ncd_report_full_en.pdf. 2010.

2. World Health Organization. Global Status Report on Non-Communicable Diseases 2014. Geneva, Switzerland. Web site. http://www.who.int/nmh/publications/ncd-status-report-2014/en/. 2014

3. World Health Organization. Noncommunicable diseases. Web site: http://www.who.int/mediacentre/factsheets/fs355/en/. 2015

4. World Health Organization. Global Health Observatory (GHO) data. Web site. http://www.who.int/gho/ncd/en/. 2012.

5. Snyder LB. Health communication campaigns and their impact on behavior. J Nutr Educ Behav. 2007; 39(2 Suppl): S32-S40.

6. Wikstrom, K, Lindstrom J, Tuomilehto J, et al. Socio-economic differences in dysglycemia and lifestyle-related risk factors 
in the Finnish middle-aged population. Eur J Public Health. 2011; 21(6): 768-774. doi: 10.1093/eurpub/ckq164

7. Hankonen N, Absetz P, Haukkala A, Uutela A. Socioeconomic status and psychosocial mechanisms of lifestyle change in a type 2 diabetes prevention trial. Ann Behav Med. 2009; 38(2): 160-165. doi: 10.1007/s12160-009-9144-1

8. Wikstrom $\mathrm{K}$, Lindstrom $\mathrm{J}$, Tuomilehto $\mathrm{J}$, et al. National diabetes prevention program (DEHKO): Awareness and self-reported lifestyle changes in Finnish middle-aged population. Public Health. 2015; 129(3): 210-217. doi: 10.1016/j. puhe.2014.12.019

9. Parmar P, Rathod GB, Rathod S, Goyal R, Aggarwal S, Parikh A. Study of knowledge, attitude and practice of general population of Gandhinagar towards hypertension. Int J Curr Microbiol App Sci. 2014; 3(8): 680-685. Web site. http://www.ijcmas.com/ vol-3-8/Pragnesh\%20Parmar,\%20et\%20al.pdf. Accessed March 14,2016

10. Bollu M, Nalluri KK, Surya Prakash A, Naga Lohith M, Venkataramarao N. Study of knowldege, attitude, and practice of general population of Guntur toward silent killer diseases: Hypertension and Diabetes. Asian J Pharm Clin Res. 2015; 8(4): 74-78.

11. Vaidya A, Aryal UR, Krettek A. Cardiovascular health knowledge, attitude and practice/behaviour in an urbanising community of Nepal: A population-based cross-sectional study from Jhaukhel-Duwakot Health Demographic Surveillance Site. BMJ Open. 2013; 3(1): e002976. doi: 10.1136/bmjopen-2013-002976

12. Kivimaki M, Jokela M, Nyberg ST, et al. Long working hours and risk of coronary heart disease and stroke: A systematic review and meta-analysis of published and unpublished data for 603,838 individuals. Lancet. 2015; 386(10005): 1739-1746. doi: 10.1016/S0140-6736(15)60295-1

13. Lim SS, Vos T, Flaxman AD, et al. A comparative risk assessment of burden of disease and injury attributable to 67 risk factors and risk factor clusters in 21 regions, 1990-2010: A systematic analysis for the Global Burden of Disease Study 2010. Lancet. 2012; 380(9859): 2224-2260. doi: 10.1016/S01406736(12)61766-8

14. Schweitzer KS, Chen SX, Law S, et al. Endothelial disruptive proinflammatory effects of nicotine and e-cigarette vapor exposures. Am J Physiol Lung Cell Mol Physiol. 2015; 309(2): L175-L187. doi: 10.1152/ajplung.00411.2014

15. Lee IM, Shiroma EJ, Lobelo F, Puska P, Blair SN, Katzmarzyk PT, Lancet Physical Activity Series Working Group. Effect of physical inactivity on major non-communicable diseases worldwide: An analysis of burden of disease and life expectancy. Lancet. 2012; 380(9838): 219-229. doi: 10.1016/S0140-

\section{6(12)61031-9}

16. Sathish T, Oldenberg B. Cluster Randomised Controlled Trial of Community-based Diabetes Prevention: The Kerala Diabetes Prevention Program. Anchorage Alaska, USA: IEA World Congress of Epidemiology; 2014: 17-21

17. Daivadanam M, Absetz P, Sathish T, et al. Lifestyle change in Kerala, India: needs assessment and planning for a community-based diabetes prevention trial. BMC Public Health. 2013; 13: 95. doi: 10.1186/1471-2458-13-95

18. Li GI, Zhang P, Wang J, et al.The long-term effect of lifestyle interventions to prevent diabetes in the China Da Qing Diabetes Prevention Study: a 20-year follow-up study. Lancet. 2008; 371(9626): 1783-1789. doi: 10.1016/S0140-6736(08)60766-7

19. Lindstrom J, Ilanne-Parikka P, Peltonen M, et al, Finnish Diabetes Prevention Study Group. Sustained reduction in the incidence of type 2 diabetes by lifestyle intervention: follow-up of the Finnish Diabetes Prevention Study. Lancet. 2006; 368(9548): 1673-1679. doi: 10.1016/S0140-6736(06)69701-8 